\title{
FITOMASSA DE ADUBOS VERDES E CONTROLE DE PLANTAS DANINHAS EM DIFERENTES DENSIDADES POPULACIONAIS DE LEGUMINOSAS'
}

\author{
MARCELO FERREIRA FERNANDES², ANTÔNIO CARLOS BARRETO ${ }^{3}$ e JOÃO EMÍDIO FILHO ${ }^{4}$
}

\begin{abstract}
RESUMO - O objetivo deste trabalho foi avaliar a fitomassa de calopogônio, mucuna-preta, mucunarajada, feijão-de-porco, guandu de porte alto, Crotalaria spectabilis e C. breviflora sob diferentes densidades de semeadura $\left(10,20,40,80\right.$ e 160 sementes viáveis $\left.\mathrm{m}^{-2}\right)$, e o crescimento de plantas daninhas nessas densidades, em área de tabuleiros costeiros. O experimento foi desenvolvido de maio a agosto de 1996, no Campo Experimental "Antônio Martins" (EMDAGRO/Embrapa-CPATC), em Lagarto, SE. O número de plantas vivas na floração (NPVF) e a matéria seca da parte aérea das leguminosas (MSPA) foram determinados quando, em cada espécie, cerca de $50 \%$ das plantas floresceram. Maiores incrementos de MSPA, em resposta ao adensamento populacional, foram observados em C. spectabilis e C. breviflora, seguidas pelo calopogônio, mucuna-preta e mucuna-rajada. Em relação ao feijão-de-porco, a resposta foi negativa, enquanto com o guandu não houve influência. Quanto ao NPVF, as respostas ao adensamento foram lineares e positivas em C. spectabilis, C. breviflora e calopogônio, e quadráticas com ponto de máxima em feijão-de-porco, guandu e mucuna-rajada. Embora nenhum modelo tenha sido ajustado para expressar a relação entre NPVF e adensamento na semeadura de mucuna-preta, a sobrevivência dessa espécie foi reduzida em todas as densidades. Maiores inibições de plantas daninhas ocorreram nas parcelas de mucuna-preta e feijão-de-porco.
\end{abstract}

Termos para indexação: culturas de cobertura, manejo do solo, competição, agricultura sustentável.

\section{DRY MATTER OF GREEN MANURE AND CONTROL OF WEEDS AT DIFFERENT SOWING LEGUME DENSITIES}

\begin{abstract}
The objective of this study was to evaluate the dry matter yields of Calopogonium mucunoides, Stizolobium aterrimum, Stizolobium deeringeanum variety "rajada", Canavalia ensiformis, Cajanus cajan, Crotalaria breviflora and C. spectabilis in relation to the sowing densities of 10, 20,40, 80 and 160 seeds $\mathrm{m}^{-2}$, and the yield of weeds grown in these legume densities. This study was carried out from May to August 1996, in a coastal tableland area of the Antonio Martins Experimental Station (EMDAGRO/Embrapa-CPATC), at Lagarto, State of Sergipe, Brazil. The number of survival plants and the dry matter yields were determined when each species reached the flowering stage. The highest increments of dry matter yield in response to increasing levels of sowing density were observed in plants of Crotalaria spectabilis and C. breviflora followed by C. mucunoides, $S$. aterrimum and $S$. deeringeanum. A negative response to the increasing sowing densities was observed in Canavalia ensiformis and sowing densities did not affect the dry matter yield of Cajanus cajan plants. Linear and positive responses of $C$. spectabilis, $C$. breviflora and $C$. mucunoides, and quadratic responses of $C$. ensiformis, $C$. cajan and $S$. deeringeanum were obtained for number of plants in response to increasing sowing density. No equations were found to express the relation between the number of survival plants and sowing densities of $S$. aterrimum, but the survival of this species at high populations was very low. $S$. aterrimum and $C$. ensiformis showed the best weed inhibition, even in the lower sowing densities.
\end{abstract}

Index terms: cover crop, soil management, competition, sustainable agriculture.

\footnotetext{
${ }^{1}$ Aceito para publicação em 12 de janeiro de 1999.

${ }^{2}$ Eng. Agr., M.Sc., Embrapa-Centro de Pesquisa Agropecuária dos Tabuleiros Costeiros (CPATC), Av. Beira-Mar, 3250, Caixa Postal 44, CEP 49001-970 Aracaju, SE. E-mail: marcelo@cpatc.embrapa.br
}

\footnotetext{
${ }^{3}$ Eng. Agr., Dr., Embrapa-CPATC.

${ }^{4}$ Eng. Agr., Empresa de Desenvolvimento Agropecuário de Sergipe (EMDAGRO), Centro Administrativo Gov. Augusto Franco, BR 235, km 4, Caixa Postal 297, CEP 49080-190 Aracaju, SE.
} 


\section{INTRODUÇÃO}

Uma das principais limitações à produtividade agrícola nos tabuleiros costeiros é a reduzida capacidade de retenção de água e nutrientes dos solos (Haynes, 1970). Características como alto teor de areia na composição textural, presença de argilas de baixa atividade e baixos teores de matéria orgânica são determinantes para essa condição. O manejo da matéria orgânica em solos com tais características é de grande importância, já que esta é responsável por $56 \%$ a $82 \%$ da CTC dos solos tropicais (Raij, 1981).

A adubação verde, consorciada ou em sucessão de culturas, tem sido sugerida como prática para manutenção ou elevação do teor de matéria orgânica no solo (Derpsch et al., 1991; Testa et al., 1992; Calegari, 1995; Galantini \& Rosell, 1997; Lal, 1997; Reeves, 1997).

Além de fixarem nitrogênio atmosférico quando associadas aos rizóbios, as leguminosas apresentam outras vantagens para serem utilizadas como adubos verdes. As maiores quantidades de lignina adicionadas ao solo foram observadas em sistemas de cultura que incluíam leguminosas tropicais perenes, o que significa que essas espécies são as de maior potencial para elevar o teor de húmus do solo (Lassus, 1990). De acordo com Testa et al. (1992), nos sistemas de rotação em que foram utilizadas leguminosas tropicais as quantidades de carbono adicionadas ao solo foram maiores do que naqueles nas quais não foram incluídas. Neste estudo, a capacidade de troca catiônica correlacionou-se positivamente com os teores de $\mathrm{C}$ encontrados no solo. O crescimento superior de plantas de milho em sucessão a leguminosas, comparativamente a outros sistemas de culturas, foi atribuído ao fornecimento de $\mathrm{Ne}$ às melhores condições de umidade e temperatura do solo resultantes da cobertura deixada pelos resíduos de leguminosas (Bragagnolo \& Mielniczuk, 1990). A importância da inclusão de leguminosas em sistemas de culturas que visam à conservação da matéria orgânica e à redução da degradação do solo tem sido citada por diversos outros autores (Galantini \& Rosell, 1997; Lal, 1997).

No entanto, além da escolha da espécie a ser utilizada como adubo verde, o grau de sucesso obtido com a utilização dessa prática é altamente depen- dente da quantidade de fitomassa adicionada ao solo (Kuo et al., 1997). Desta forma, a determinação da população ótima de diversas leguminosas, para produção de fitomassa com fins de incorporação ao solo, é fundamental para a maximização dos efeitos da prática de adubação verde. Para diversas culturas, isto está bem estabelecido, tendo sido observado que, além de uma determinada população, ocorre a estabilização ou redução da produtividade em função da competição intra-específica por água, nutrientes, luz e outros recursos (Holliday, 1960; Silva et al., 1983; Benassi \& Abrahão, 1991; Silva \& Nepomuceno, 1991). Além disso, a densidade de semeadura das leguminosas apresenta forte influência sobre o controle de plantas daninhas, em decorrência do maior ou menor sombreamento.

O objetivo deste trabalho foi avaliar a produtividade de fitomassa de leguminosas para adubação verde em diferentes densidades de semeadura a lanço e a produtividade de plantas daninhas nas parcelas cultivadas com essas leguminosas, em solo de tabuleiros costeiros.

\section{MATERIAL E MÉTODOS}

O experimento foi desenvolvido em um solo Podzólico Amarelo distrófico latossólico, característico dos tabuleiros costeiros, na Estação Experimental "Antônio Martins", do Convênio Embrapa/EMDAGRO, no município de Lagarto, SE, de maio a agosto de 1996. Os resultados das análises químicas do solo são expressos a seguir: matéria orgânica pelo método de Walkley-Black (Jackson, 1958) $=21,03 \mathrm{~g} \mathrm{dm}^{-3} ; \mathrm{pH}$ em água $(1: 2,5)=4,6 ; \mathrm{Ca}+\mathrm{Mg}=$ $0,7 \mathrm{cmol}_{\mathrm{c}} \mathrm{dm}^{-3}, \mathrm{Al}=0,3 \mathrm{cmol}_{\mathrm{c}} \mathrm{dm}^{-3}$ e Na$=0,07 \mathrm{cmol}_{\mathrm{c}} \mathrm{dm}^{-3}$, extraídos com $\mathrm{KCl} 1 \mathrm{~mol} \mathrm{~L}^{-1}$ e determinados por titulometria (Embrapa, 1979); $\mathrm{Al}+\mathrm{H}=2,1 \mathrm{cmol}_{\mathrm{c}} \mathrm{dm}^{-3}$, extraídos por acetato de cálcio $0,5 \mathrm{~mol} \mathrm{~L}^{-1} \mathrm{e}$ determinados por titulometria (Embrapa, 1979); $\mathrm{P}=5 \mathrm{mg} \mathrm{dm}^{-3} \mathrm{e}$ $\mathrm{K}=0,08 \mathrm{cmol}_{\mathrm{c}} \mathrm{dm}^{-3}$, extraídos pelo Mehlich-1, sendo os teores de $\mathrm{P}$ determinados por colorimetria (Braga \& Defelipo, 1974) e os de K, por fotometria de chama (Embrapa, 1979). Os resultados da análise granulométrica, pelo método do densímetro (Embrapa, 1979), revelaram os seguintes resultados: areia $=840 \mathrm{~g} \mathrm{~kg}^{-1}$, silte $=60 \mathrm{~g} \mathrm{~kg}^{-1}$ e argila $=100 \mathrm{~g} \mathrm{~kg}^{-1}$.

Foram testadas cinco densidades de semeadura $(10,20$, 40,80 e 160 sementes viáveis $\mathrm{m}^{-2}$ ) quanto às leguminosas: calopogônio (Calopogonium mucunoides), mucuna-preta (Stizolobium aterrimum), mucuna-rajada (Stizolobium 
deeringeanum variedade rajada), feijão-de-porco (Canavalia ensiformis), guandu de porte alto (Cajanus cajan), Crotalaria spectabilis e Crotalaria breviflora. $\mathrm{O}$ delineamento experimental foi o de blocos ao acaso, em parcelas subdivididas, com três repetições. As dimensões das parcelas, correspondentes às espécies de leguminosas, foram de $2 \mathrm{~m} \times 10 \mathrm{~m}$, e as das subparcelas, que corresponderam às densidades de semeadura e distribuídas aleatoriamente, foram de $2 \mathrm{~m} \times 2 \mathrm{~m}$.

Para garantir que cerca de $10,20,40,80$ e 160 sementes viáveis, ou seja, com potencial para produzir populações equivalentes de plantas vivas, fossem distribuídas por $\mathrm{m}^{2}$, as quantidades de sementes utilizadas foram calculadas considerando-se os resultados dos testes de germinação. Desta forma, considerou-se o número de sementes $\mathrm{m}^{-2} \mathrm{em}$ cada densidade como sendo equivalente ao número de plantas iniciais por $\mathrm{m}^{2}$ das respectivas subparcelas.

A área recebeu calcário dolomítico $\left(1.000 \mathrm{~kg} \mathrm{ha}^{-1}\right) \mathrm{e}$ adubações com superfosfato simples $\left(120 \mathrm{~kg} \mathrm{ha}^{-1} \mathrm{de}_{2} \mathrm{O}_{5}\right)$ e cloreto de potássio $\left(45 \mathrm{~kg} \mathrm{ha}^{-1}\right.$ de $\left.\mathrm{K}_{2} \mathrm{O}\right)$, a lanço, respectivamente um mês e uma semana antes da semeadura. Tais materiais foram incorporados até $20 \mathrm{~cm}$ de profundidade. As sementes foram distribuídas a lanço nas subparcelas e incorporadas manualmente.

Quando 50\% das plantas de cada espécie estavam em floração, as partes aéreas das leguminosas e das plantas daninhas, crescidas em $1 \mathrm{~m}^{2}$ no centro de cada subparcela, foram cortadas no nível do solo, secas em estufa a $65^{\circ} \mathrm{C}$, por 72 horas, e determinada a massa da matéria seca da parte aérea (MSPA). Para avaliar a intensidade de competição intra-específica em cada uma das densidades de semeadura, procedeu-se a contagem do número de plantas vivas na floração $\mathrm{m}^{-2}$ (NPVF) e o cálculo da matéria seca produzida por planta (MSPAP), pela razão entre MSPA e NPVF.

Realizaram-se análises de variância e ajustamento de equações de regressão para descrever o comportamento das espécies em função da densidade de semeadura. Como não foi realizado o desbaste das subparcelas, consideraram-se apenas as repetições cujo número de plantas obtido na colheita não excedeu em $25 \%$ ao número proposto para cada densidade de semeadura. Esse excesso foi observado em uma subparcela do tratamento com 40 sementes $\mathrm{m}^{-2}$ da mucuna-rajada e em uma com 20 sementes $\mathrm{m}^{-2}$ do guandu.

\section{RESULTADOS E DISCUSSÃO}

O período decorrido entre o plantio e a observação de floração em $50 \%$ das plantas foi de 83 dias para C. breviflora e para mucuna-rajada, 96 dias para
C. spectabilis, 146 dias para calopogônio e guandu, 115 dias para mucuna-preta e 130 dias para feijão-deporco.

Com relação à matéria seca da parte aérea (MSPA), as maiores respostas ao adensamento populacional na semeadura foram observadas nas parcelas com Crotalaria breviflora e Crotalaria spectabilis (Fig. 1). Essas respostas foram lineares e resultaram no aumento da MSPA de 394\% em C. breviflora e de $413 \%$ em C. spectabilis, em função do aumento de 10 para 160 sementes $\mathrm{m}^{-2}$. As plantas dessas espécies apresentam crescimento ereto e porte de baixo a médio (Calegari, 1995), além de uma arquitetura cônica, com folíolos mais largos na base e menores na parte superior do caule. Tais características levam ao baixo sombreamento das plantas e redução da

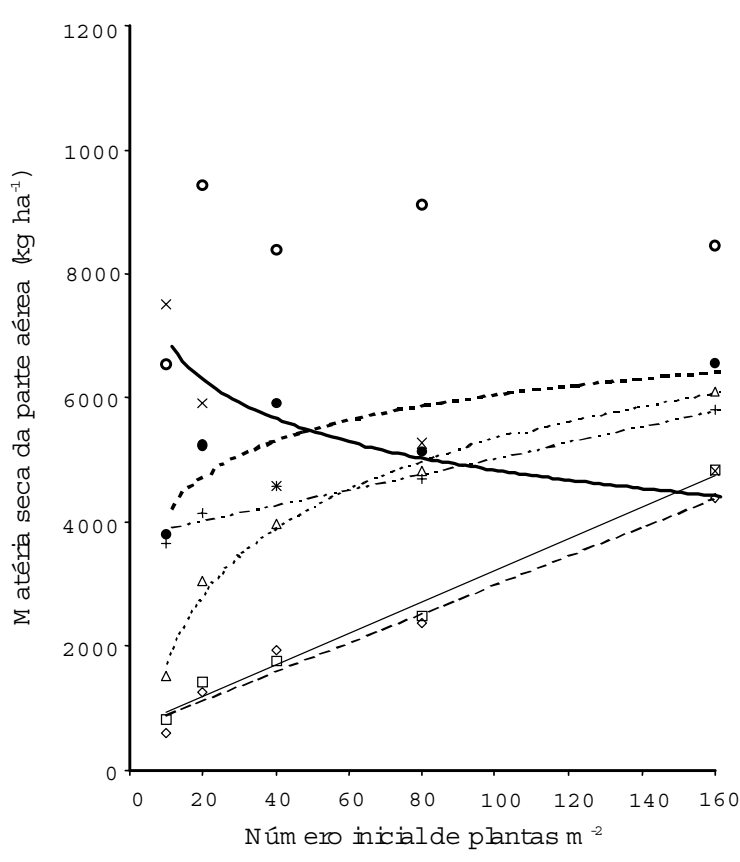

\begin{tabular}{|c|c|c|c|}
\hline & C. brevifbra & $y=25,593 x+672,58$ & $R^{2}=0,986^{*}$ \\
\hline $8^{---}$ & C. spectabilis & $y=23,350 x+654,52$ & $\mathrm{R}^{2}=0,970 * *$ \\
\hline & Cabpogôni & $y=1578 \operatorname{Ln}(x)-1923$ & $\mathrm{R}^{2}=0,989 * *$ \\
\hline & Feigao-de-porco & $y=-864 \operatorname{In}(x)+8813$ & $\mathrm{R}^{2}=0,655^{*}$ \\
\hline 0 & Guandu & Não-significativo & \\
\hline$+-\cdots-$ & M ucuna-rajäda & $y=12,628 x+3791,4$ & $\mathrm{R}^{2}=0,934$ * \\
\hline & M ucuna-preta & $y=781 \operatorname{Ln}(x)+2449$ & $\mathrm{R}^{2}=0,700 *$ \\
\hline
\end{tabular}

FIG. 1. Relação entre a produtividade de matéria seca da parte aérea de leguminosas e a densidade populacional inicial $(* \mathrm{e} * *$ significativo a $5 \%$ e $1 \%$, respectivamente).

Pesq. agropec. bras., Brasília, v.34, n.9, p.1593-1600, set. 1999 
competição por luz, permitindo o estabelecimento de maior número de plantas por área. Na semeadura a lanço, Calegari (1995) recomenda a utilização de $15 \mathrm{~kg} \mathrm{ha}^{-1}$ de sementes de $C$. spectabilis e $24 \mathrm{~kg} \mathrm{ha}^{-1}$ de sementes de C. breviflora. Convertendo-se esses dados para número de sementes $\mathrm{m}^{-2}$, obtêm-se as densidades de 86 e 133 sementes $\mathrm{m}^{-2}$ em C. breviflora e C. spectabilis, respectivamente. De acordo com o presente estudo, esses valores podem ser mais elevados, pelo menos nas condições onde o ensaio foi realizado, sem que haja perda da produtividade de fitomassa a ser incorporada ao solo.

A reduzida competição nas maiores densidades pode ser confirmada pela observação de que o número de plantas vivas na floração (NPVF), em relação ao número inicial de plantas por $\mathrm{m}^{2}$, foi elevado em ambas as espécies, mesmo nas maiores populações (Fig. 2). Além disso, a produtividade de matéria
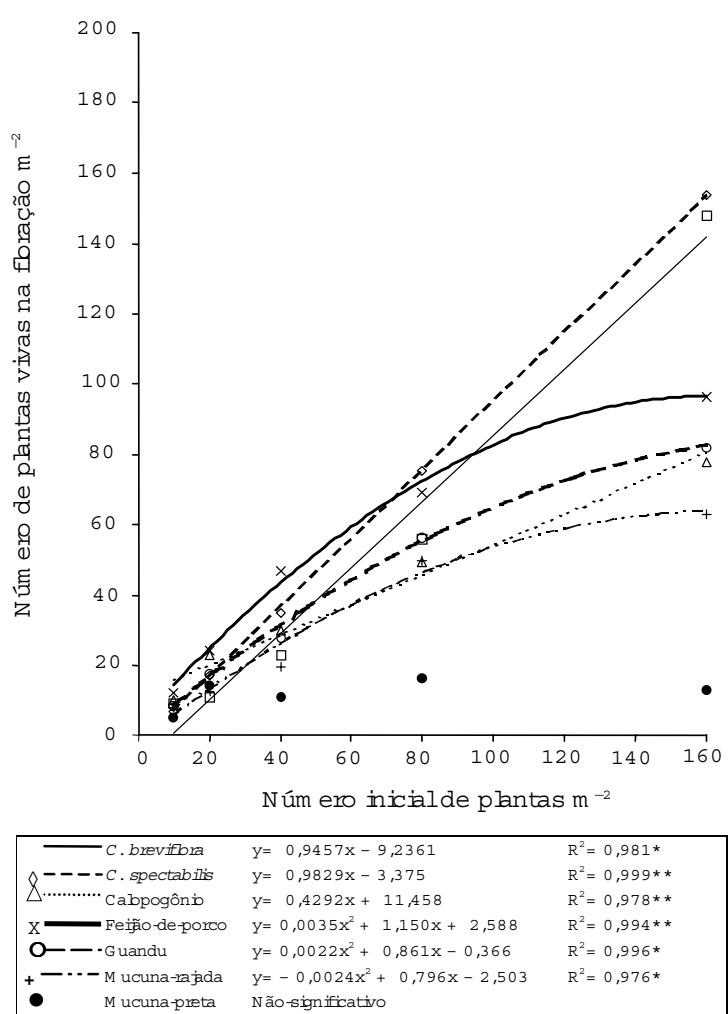

FIG. 2. Relação entre o número de plantas vivas na floração e a densidade populacional inicial (* e ** significativo a $5 \%$ e $1 \%$, respectivamente). seca da parte aérea por planta (MSPAP) dessas crotalárias foi reduzida apenas três vezes em função do aumento da densidade de semeadura de 10 para 160 sementes $\mathrm{m}^{-2}$ (Fig. 3), sendo esta uma das menores reduções observadas neste estudo.

Embora as duas crotalárias apresentem características morfológicas e capacidade de sombreamento similares, o efeito inibitório de $C$. spectabilis sobre a produtividade de matéria seca de plantas daninhas (MSPD) foi maior e menos dependente do adensamento populacional que o de C. breviflora (Fig. 4). Tal diferença na capacidade de inibição da produtividade de MSPD deve estar associada à maior largura das folhas de C. spectabilis em relação ao da C. breviflora, ou ainda a um possível efeito alelopático mais acentuado desta primeira em rela-

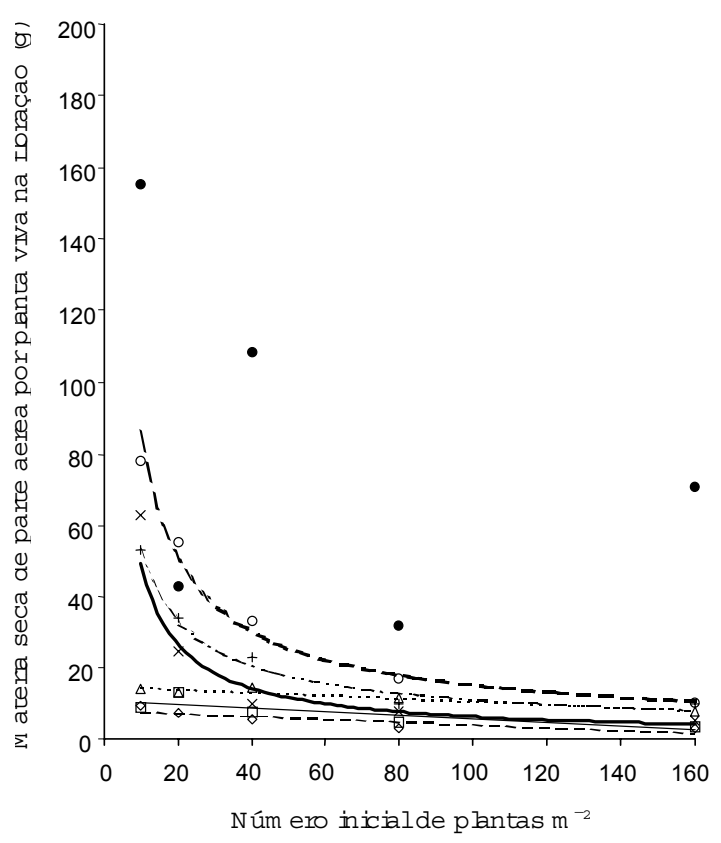

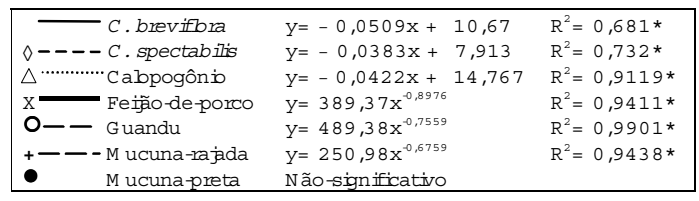

FIG. 3. Relação entre a produtividade de matéria seca da parte aérea por planta das leguminosas e a densidade populacional inicial ("significativo a $5 \%$ ) . 
ção à segunda. Diferenças na intensidade do efeito alelopático de diversas plantas utilizadas para adubação verde já foram descritas por Almeida \& Rodrigues (1985) e Almeida (1988).

Nas parcelas com as mucunas preta e rajada observou-se um menor incremento da MSPA em resposta ao adensamento populacional, com ganhos de $51 \%$ e $48 \%$, respectivamente, em conseqüência do aumento da densidade de 10 para 160 sementes $\mathrm{m}^{-2}$. A mucuna-preta apresenta razoável tolerância ao sombreamento, embora seja requerida insolação adequada para seu rápido crescimento (Calegari, 1995). Em função de seu hábito rasteiro e vigoroso (Miyasaka, 1984), a competição por luz entre as plantas dessa espécie pode ser muito acentuada à medida que o adensamento é aumen-

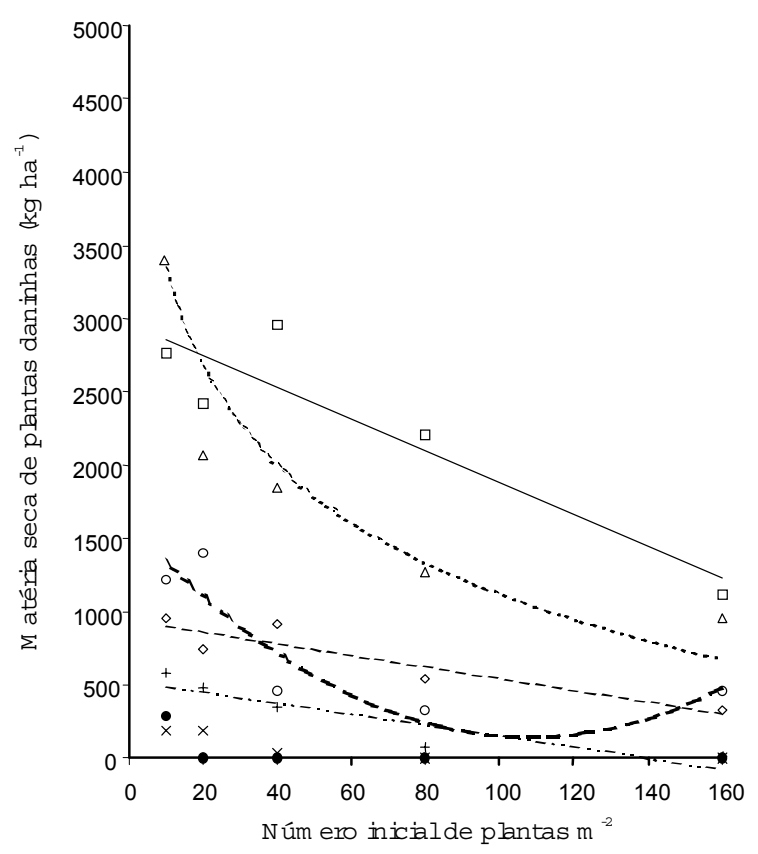

\begin{tabular}{|c|c|c|}
\hline C. breviflora & $y=-10,835 x+2964,7$ & $\mathrm{R}^{2}=0,842 * *$ \\
\hline$\Delta----C$. spectabilis & $y=-4,0003 x+944,3$ & $\mathrm{R}^{2}=0,851 *$ \\
\hline -Cabpogônio & $y=-956,61 \operatorname{Ln}(x)+5533,4$ & $\mathrm{R}^{2}=0,856 *$ \\
\hline Feĩ̃o-de-porco & Não-significațio & \\
\hline O- Guandu & $y=0,1246 x^{2}-26,954 x+1596,1$ & $\mathrm{R}^{2}=0,822 * *$ \\
\hline +-ー-M ucuna-rajada & $y=-3,7268 x+526,39$ & $\mathrm{R}^{2}=0,840 * *$ \\
\hline M ucuna-preta & Não-significativo & \\
\hline
\end{tabular}

FIG. 4. Relação entre a produtividade de matéria seca da parte aérea de plantas daninhas em parcelas cultivadas com leguminosas e a densidade populacional destas (* $\mathrm{e}^{* *}$ significativo a $5 \%$ e $1 \%$, respectivamente). tado. Visto que a intensidade e a distribuição de chuvas foram adequadas durante o período no qual o experimento foi realizado e que foram feitas correções do solo e adubações com P e K na área, a luminosidade deve ter sido o principal fator limitante ao incremento da MSPA da mucuna-preta. De acordo com compilação de dados sobre a composição química de 22 leguminosas para adubação verde, realizada por Calegari (1995), observou-se que as plantas de mucuna-preta estão entre as de menor exigência nos nutrientes $\mathrm{P}, \mathrm{K}, \mathrm{Ca}$ e $\mathrm{Mg}$. A mucuna-rajada apresenta o mesmo tipo de crescimento rasteiro e vigoroso, porém o ciclo de suas plantas é menor que o das de mucuna-preta.

Nenhum dos modelos matemáticos testados foi significativo para descrever o efeito do adensamento da mucuna-preta sobre a MSPAP, o NPVF e a MSPD. No entanto, pôde-se observar que o NPVF foi muito reduzido comparativamente ao número de sementes utilizadas, principalmente nas densidades maiores que 40 sementes viáveis $\mathrm{m}^{-2}$ (Fig. 2), e que a supressão total da MSPD ocorreu nas parcelas com $20 \mathrm{ou}$ mais sementes $\mathrm{m}^{-2}$ (Fig. 4).

A resposta da mucuna-rajada ao adensamento, em termos de NPVF, foi quadrática, com máximo de 63 plantas na densidade de 166 sementes $\mathrm{m}^{-2}$ (Fig. 2), de acordo com a equação ajustada para esta variável. Essa leguminosa apresentou baixa proporção entre o NPVF e o número de sementes utilizadas na semeadura, nas diferentes densidades. A inibição da produtividade de MSPD pela mucuna-rajada também foi eficiente, embora a supressão total só tenha sido atingida na densidade de 141 sementes $\mathrm{m}^{-2}$. A diferença na capacidade de inibição da produtividade de MSPD entre as mucunas estudadas pode ser conseqüência da maior velocidade de crescimento inicial ou da produção de substâncias alelopáticas pela mucuna-preta. Reduções na produção de feijoeiro em sucessão ao plantio de mucuna-preta já foram observadas por Abboud \& Duque (1986), que supõem que esse efeito possa estar associado a substâncias alelopáticas produzidas por essa espécie.

O calopogônio, apesar de seu hábito rasteiro, semelhante ao das mucunas, apresentou um incremento de $256 \%$ da MPAS, em resposta à elevação da densidade de semeadura de 10 para 160 sementes $\mathrm{m}^{-2}$. Observou-se que essa resposta foi logarítmica, de 
forma que o incremento da MPAS foi sendo reduzido à medida que a densidade de semeadura foi aumentada (Fig. 1). Diferentemente das mucunas, as plantas dessa espécie apresentam baixa velocidade de crescimento inicial (Calegari, 1995), o que resulta em um maior período de crescimento sem competição pelos recursos disponíveis. No entanto, sob maiores densidades de semeadura, a grande proximidade entre as plantas resulta em menor período livre de competição, conduzindo a um sombreamento precoce e à redução da resposta ao adensamento.

Em relação ao NPVF, a resposta do calopogônio ao adensamento foi linear. A equação que descreve essa resposta apresentou um coeficiente angular pequeno $(0,429)$, indicando uma acentuada redução das populações, nas maiores densidades de semeadura. Tal redução pode ser explicada pelo hábito de crescimento rasteiro e pela baixa tolerância do calopogônio ao sombreamento (Calegari, 1995). A diminuição do NPVF foi o principal mecanismo de ajuste do calopogônio às altas densidades, já que, a redução da MSPAP, em função do adensamento, foi a menor entre todas as leguminosas estudadas. A MSPAP desta espécie na densidade de 160 sementes $\mathrm{m}^{-2}$ foi equivalente a $56 \%$ da produzida nas parcelas com 10 sementes $\mathrm{m}^{-2}$.

A reduzida velocidade de crescimento inicial também determinou a elevada produtividade de MSPD nas parcelas de calopogônio com 10 sementes $\mathrm{m}^{-2}$ (3.330 kg ha-1) (Fig. 4). No entanto, com o adensamento houve uma cobertura mais rápida do solo, com redução da MSPD nas parcelas. Na maior densidade de semeadura, a MSPD foi reduzida a $20 \%$ da observada na menor densidade. Resultados semelhantes foram obtidos com tremoço-branco, no Paraná (Derpsch et al., 1991). De acordo com esses autores, o aumento da densidade de semeadura na cultura desta leguminosa é necessário para a supressão de ervas daninhas, em função da lenta velocidade de crescimento e de cobertura do solo por esta.

O feijão-de-porco foi a única espécie em que se observou redução da MSPA, em função do adensamento na semeadura (Fig. 1). Essa redução foi logarítmica, e a MSPA na maior densidade foi cerca de $65 \%$ da observada na menor. A rápida velocidade de crescimento, a arquitetura ramificada e os folíolos largos, característicos dessa espécie podem ter resultado em um maior sombreamento das plantas, incorrendo em aumento da competição por luz com o incremento da densidade. Alguns autores têm relatado que o feijão-de-porco apresenta tolerância razoável ao sombreamento (Calegari, 1995), de forma que a competição por outros recursos também pode ter sido limitante para essa espécie. Em compilação de trabalhos sobre composição química da matéria seca de 22 leguminosas, citada anteriormente, o feijão-de-porco foi a espécie em que se verificou o maior teor de $\mathrm{K}(5,62 \%)$ e o quarto maior teor de $\mathrm{Mg}$ $(0,63 \%)$. O adensamento de populações de plantas resulta em uma menor exploração do solo pelo sistema radicular (Haynes \& Sayre, 1956), colaborando para uma competição mais intensa entre plantas pelos nutrientes disponíveis (Tomas, 1979). O conjunto das observações acima permite supor que a limitação imposta ao crescimento, em função do adensamento, possa ser de natureza nutricional ou hídrica. Os resultados obtidos no presente trabalho corroboram as recomendações de densidade de semeadura feitas por Miyasaka (1984) e Calegari (1995) que, convertidas para as unidades aqui utilizadas, foram de aproximadamente 11 sementes $\mathrm{m}^{-2}$.

$\mathrm{O}$ máximo de NPVF, de acordo com a equação ajustada, foi de 92 plantas $\mathrm{m}^{-2}$, na densidade de 164 sementes $\mathrm{m}^{-2}$ (Fig. 2), o que corresponde a $56 \%$ de plantas vivas em relação ao número de sementes utilizadas na semeadura. Nessa espécie houve a maior redução de MSPAP, em função do adensamento, observando-se, no tratamento com 160 sementes $\mathrm{m}^{-2}$, cerca de $8,3 \%$ da MSPAP encontradas nas parcelas com 10 sementes $\mathrm{m}^{-2}$ (Fig. 3). Apesar de nenhum dos modelos matemáticos avaliados ter sido adequado para descrever a resposta da MSPD em função do adensamento populacional do feijão-deporco, observou-se que essa produtividade foi extremamente reduzida em todas as populações da leguminosa (Fig. 4). A alta capacidade de inibição da MSPD pelas plantas dessa espécie pode ser atribuída à rápida cobertura do solo e a efeitos alelopáticos, os quais, de acordo com Calegari (1995), podem inibir até mesmo a tiririca (Cyperus rotundus), de difícil controle.

Com relação ao guandu, não foi verificada uma resposta consistente ao adensamento populacional, em termos de MSPA (Fig. 1), cuja produtividade os- 
cilou entre 6,5 e 9,5 $\mathrm{tha}^{-1}$. Observou-se que as plantas crescidas na menor densidade populacional, apresentaram caules de cerca de $3 \mathrm{~cm}$ de diâmetro, enquanto nas maiores densidades o diâmetro médio dos caules foi de $1 \mathrm{~cm}$. Assim, embora o adensamento das populações de guandu não tenha resultado em contribuição significativa na MSPA, a redução do diâmetro dos caules nas maiores populações apresenta grande importância prática, já que a espessura do caule dessa espécie é um dos fatores limitantes ao seu manejo como adubo verde (Miyasaka, 1984).

Observou-se resposta quadrática ao adensamento no tratamento com guandu, em termos de NPVF, com um máximo de 84 plantas $\mathrm{m}^{-2}$, obtidas na densidade de 196 sementes $\mathrm{m}^{-2}$ (Fig. 2). Houve uma redução de cerca de oito vezes na MSPAP dessa leguminosa, entre as densidades de 10 e 160 sementes $\mathrm{m}^{-2}$ (Fig. 3). A MSPD nas parcelas com o guandu apresentou resposta quadrática ao adensamento, com um mínimo de $142,5 \mathrm{~kg} \mathrm{ha}^{-1}$ na população de 108 sementes $\mathrm{m}^{-2}$ (Fig. 4). Por ser uma espécie de sistema radicular vigoroso (Miyasaka, 1984) e porte muito alto (Wildner \& Dadalto, 1991), o adensamento das populações de guandu pode ter resultado em competição por nutrientes, água e sombreamento acentuados. A relação entre altura de planta e densidade de semeadura também já foi observada em girassol (Silva \& Nepomuceno, 1991). De acordo com esses autores, com as variedades de girassol precoce e de baixa estatura pode-se utilizar maior densidade populacional, sem perda de produtividade, ao contrário de se utilizar as variedades tardias e de porte alto.

\section{CONCLUSÕES}

1. As respostas ao adensamento na semeadura são mais efetivas com as leguminosas eretas, de baixa a média estatura, e de arquitetura cônica.

2. Nas leguminosas rasteiras de rápido crescimento há menor resposta ao adensamento na semeadura e maior controle das plantas daninhas do que nas rasteiras de crescimento lento.

3. A produtividade de matéria seca de parte aérea do feijão-de-porco decresce com o incremento das densidades de semeadura de 10 para 160 sementes viáveis $\mathrm{m}^{-2}$.
4. O feijão-de-porco é muito eficiente no controle de plantas daninhas, mesmo nas menores densidades de semeadura.

\section{REFERÊNCIAS}

ABBOUD, A.C.S.; DUQUE, F.F. Efeitos de materiais orgânicos e vermiculita sobre a seqüência feijão-milhofeijão. Pesquisa Agropecuária Brasileira, Brasília, v.21, n.3, p.227-236, 1986.

ALMEIDA, F.S. A alelopatia e as plantas. Londrina: IAPAR, 1988. 60p. (IAPAR. Circular, 53).

ALMEIDA, F.S.; RODRIGUES, B.N. Plantio direto. In: ALMEIDA, F.S.; RODRIGUES, B.N. Guia de herbicidas: contribuição para o uso adequado em plantio direto e convencional. Londrina: IAPAR, 1985. p.341-399.

BENASSI, A.C.; ABRAHÃO, J.T.M. Épocas de semeadura e espaçamentos sobre a produção de fitomassa de tremoço. Pesquisa Agropecuária Brasileira, Brasília, v.26, n.9, p.1517-1522, set. 1991.

BRAGA, J.M.; DEFELIPO, B.V. Determinação espectrofotométrica de fósforo em extratos de solo e material vegetal. Revista Ceres, Viçosa, MG, v.21, p.73-85, 1974.

BRAGAGNOLO, N.; MIELNICZUK, J. Cobertura do solo por resíduos de oito seqüências de culturas e seu relacionamento com a temperatura e umidade do solo, germinação e crescimento inicial do milho. Revista Brasileira de Ciência do Solo, Campinas, v.14, p.91-98, 1990.

CALEGARI, A. Leguminosas para adubação verde de verão no Paraná. Londrina: IAPAR, 1995. 118p. (IAPAR. Circular, 80).

DERPSCH, R.; ROTH, C.H.; SIDIRAS, N.; KÖPKE, U. Importância da adubação verde. In: DERPSCH, R.; ROTH, C.H.; SIDIRAS, N.; KÖPKE, U. Controle da erosão no Paraná, Brasil: sistemas de cobertura do solo, plantio direto e preparo conservacionista do solo. Eschborn: GTZ/IAPAR, 1991. p.117-145.

EMBRAPA. Serviço Nacional de Levantamento e Conservação de Solos. (Rio de Janeiro, RJ). Manual de métodos de análise de solo. Rio de Janeiro, 1979. não paginado.

GALANTINI, J.A.; ROSELL, R.A. Organic fractions, N, $\mathrm{P}$ and $\mathrm{S}$ changes in an Argentine semiarid Haplustoll under different crop sequences. Soil and Tillage Research, v.42, p.221-228, 1997.

Pesq. agropec. bras., Brasília, v.34, n.9, p.1593-1600, set. 1999 
HAYNES, J.L. Uso agrícola dos tabuleiros costeiros do Nordeste do Brasil: um exame das pesquisas. Recife: SUDENE, 1970. 153p.

HAYNES, J.L.; SAYRE, J.D. Response of corn to withinrow competition. Agronomy Journal, v.48, p.362364, 1956.

HOLLIDAY, R. Plant population and crop yield: Part I. Review article. Field Crop Abstracts, v.13, p.159167, 1960.

JACKSON, M.L. Soil chemical analysis. New Jersey: Prentice Hall, 1958. 498p.

KUO, S.; SAINJU, U.M.; JELLUM, E.J. Winter cover crop effect on soil organic carbon and carbohydrate in soil. Soil Science Society of America. Journal, v.61, p.145-152, 1997.

LAL, R. Long-term tillage and maize monoculture effects on a tropical Afisol in western Nigeria. II. Soil chemical properties. Soil and Tillage Research, v.42, p.161-174, 1997.

LASSUS, C. de. Composição dos resíduos vegetais de um solo manejado com nove sistemas de culturas. Revista Brasileira de Ciência do Solo, Campinas, v.14, p.375-380, 1990.

MIYASAKA, S. Histórico de estudos de adubação verde, leguminosas viáveis e suas características. In: FUNDAÇÃO CARGILL (Campinas, SP). Adubação verde no Brasil. Campinas, 1984. p.64-123.
RAIJ, B. van. Avaliação da fertilidade do solo. Piracicaba: Instituto da Potassa e Fosfato, 1981. 142p.

REEVES, D.W. The role of soil organic matter in maintaining soil quality in continuous cropping systems. Soil and Tillage Research, v.43, p.131-167, 1997.

SILVA, P.R.F. da; COSTA, J.A.; MUNDSTOCK, C.M. Densidade de semeadura em girassol (Heliantus annus). Agronomia Sulriograndense, Porto Alegre, v.19, p.197-202, 1983.

SILVA, P.R.F. da; NEPOMUCENO, A.L. Efeito de arranjo de plantas no rendimento de grãos, componentes do rendimento, teor de óleo e no controle de plantas daninhas em girassol. Pesquisa Agropecuária Brasileira, Brasília, v.26, n.9, p.1503-1508, set. 1991.

TESTA, V.M.; TEIXEIRA, L.A.J.; MIELNICZUK, J. Características químicas de um podzólico vermelhoescuro afetadas por sistemas de culturas. Revista Brasileira de Ciência do Solo, Campinas, v.16, p.107-114, 1992.

TOMAS, J.C. Sistemas culturais milho-feijão: comportamento de três sistemas de cultivos associados em diferentes densidades de plantas de milho. Viçosa: UFV, Imprensa Universtária, 1979. 55p.

WILDNER, L.P.; DADALTO, G.G. Adubos verdes de verão para o Oeste Catarinense. Agropecuária Catarinense, Florianópolis, v.4, p.36-40, 1991. 